\title{
Lead Dislodgement
}

National Cancer Institute

\section{Source}

National Cancer Institute. Lead Dislodgement. NCI Thesaurus. Code C101241.

Movement of a lead away from the original implantation site. (ACC) 